Supporting Information for:

\title{
Outer-Sphere Oxidation of the Superoxide Radical Anion
} Ira A. Weinstock*

*Department of Chemistry, Ben-Gurion University of the Negev, Beer Sheva 84105, Israel.

\section{Contents:}

I. Derivation of equations 4-6 in the text

II. Calculations used to obtain the results in Figures 2 and 3 of the text

III. Table S1. Relative Magnitudes of Work Terms, $w_{\mathrm{ij}}$, and $\Delta / 2$ for Reductions of $\mathbf{O}_{2}$

IV. Rate constants for oxidations of $\mathrm{O}_{2}^{-}$by 3 additional inorganic complexes

V. Comment on reactions of phenoxyl radicals with $\mathrm{O}_{2}^{-}$

\section{Derivation of equations 4-6 in the text.}

When $r_{1} \neq r_{2}, \lambda_{12} \neq 1 / 2\left(\lambda_{11}+\lambda_{22}\right)$. This is because the outer-sphere components of $\lambda_{12}$ ( $\lambda_{11 \text { (out) }}$ and $\lambda_{22 \text { (out) }}$ ) can't be averaged. In eq 1 (with $\Delta$ defined in eq 2 ), $\lambda_{11 \text { (out) }}$ and $\lambda_{22 \text { (out) }}$ are removed, and replaced by the explicit expression for $\lambda_{12(\mathrm{out})}$ :

$$
\lambda_{12}=1 / 2\left(\lambda_{11(\text { total })}+\lambda_{22(\text { total })}+2 \Delta\right),
$$

in which, $\Delta$, is defined as shown in eq 2 :

$$
\Delta=\left(n e^{2}\right)\left(\frac{1}{2 r_{1}}+\frac{1}{2 r_{2}}-\frac{1}{\left(r_{1}+r_{2}\right)}\right)\left(\frac{1}{\eta^{2}}-\frac{1}{D_{s}}\right)-\frac{1}{2}\left(\lambda_{11(\mathrm{out})}+\lambda_{22(\mathrm{out})}\right)
$$

The cross relation (solution for $k_{12}$ ) is then derived using the more general form of $\lambda_{12}$ defined in eq 1. This removes the constraint, inherent in the familiar form of the Marcus cross relation, that the reacting species possess the same radii. Key steps are as follows:

$$
\begin{aligned}
& k_{11}^{0}=Z \exp \left\{-\left(w_{11}^{0}+\frac{\lambda_{11}}{4}\right) / R T\right\} \\
& \ln k_{11}^{0}=\ln Z-\frac{w_{11}^{0}}{R T}-\frac{\lambda_{11}}{4 R T}
\end{aligned}
$$

The superscripted "0" refers to zero ionic strength. Similarly, 


$$
\begin{aligned}
& k_{22}^{0}=Z \exp \left\{-\left(w_{22}^{0}+\frac{\lambda_{22}}{4}\right) / R T\right\} \\
& \ln k_{22}^{0}=\ln Z-\frac{w_{22}^{0}}{R T}-\frac{\lambda_{22}}{4 R T}
\end{aligned}
$$

For the cross reaction, at non-zero ionic strength, $\mu$ :

$$
k_{12}^{\mu}=Z \exp \left\{-\left[w_{12}^{\mu}+\frac{\lambda_{12}}{4}\left(1+\frac{\Delta G_{12}^{o^{\prime}}}{\lambda_{12}}\right)^{2}\right] / R T\right\}
$$

And,

$$
\ln k_{12}^{\mu}=\ln Z-\frac{w_{12}^{\mu}}{R T}-\frac{\lambda_{12}}{4 R T}\left(1+\frac{\Delta G_{12}^{o^{\prime}}}{\lambda_{12}}\right)^{2}
$$

where (in eqs e and f),

$$
\Delta G_{12}^{o}=-R T \ln K_{12},
$$

and the corrected free energy is given by:

$$
\Delta G_{12}^{o^{\prime}}=\Delta G_{12}^{o}+w_{21}^{\mu}-w_{12}^{\mu}
$$

in which, $w_{21}$ and $w_{12}$ refer to the Coulombic work associated, respectively, with formation of products (successor complex) and reactants (precursor complex). Combining eqs $\mathrm{g}$ and $\mathrm{h}$ :

$$
\Delta G_{12}^{o^{\prime}}=-R T \ln K_{12}+w_{21}^{\mu}-w_{12}^{\mu}
$$

Substitution of eq i into eq $\mathrm{f}$ gives:

$$
\ln k_{12}^{\mu}=\ln Z-\frac{w_{12}^{\mu}}{R T}-\frac{\lambda_{12}}{4 R T}\left(1+\frac{-R T \ln K_{12}+w_{21}^{\mu}-w_{12}^{\mu}}{\lambda_{12}}\right)^{2}
$$

Arrangement and substitutions of eqs 1 (a function of $\Delta$ ), $\mathrm{b}$ and $\mathrm{d}$, into eq $\mathrm{j}$, gives: 


$$
\ln k_{12}^{\mu}=\ln Z-\frac{w_{12}^{\mu}}{R T}-\frac{x}{4 R T}\left(1+\frac{y}{x}\right)^{2},
$$

in which,

$$
x=2 R T\left\{\ln Z^{2}-\ln k_{11}^{0} k_{22}^{0}-\frac{w_{11}^{0}+w_{11}^{0}}{R T}+\frac{\Delta}{2 R T}\right\}
$$

and,

$$
y=-R T \ln K_{12}+w_{21}^{\mu}-w_{12}^{\mu}
$$

By solving eq $\mathrm{k}$ for $k_{12}$, and then expanding the solution using eqs 1 and $\mathrm{m}$ for $x$ and $y$, one obtains eqs 3-5 (identical to 4-6 in the text):

$$
k_{12}=\left(k_{11} k_{22} K_{12} f_{12}\right)^{1 / 2} W_{12}
$$

$\ln f_{12}=\frac{\left[\ln K_{12}+\left(w_{12}-w_{21}\right) / R T\right]^{2}}{4 \ln \left(k_{11} k_{22} / Z^{2}\right)+\left(w_{11}+w_{22}-\frac{\Delta}{2}\right) / R T}$

$W_{12}=\exp \left[-\left(w_{12}+w_{21}-w_{11}-w_{22}+\frac{\Delta}{2}\right) / 2 R T\right]$

Eq 3 is identical to the familiar form of the Marcus cross relation (MCR). However, $\ln f_{12}$ and $W_{12}$ (eqs 4 and 5) now include $\Delta$. Conceptually, eqs 3-5 are simply a more general form of the MCR that quantitatively allows for the effect of unequal reactant radii on the total solvent-reorganization energy.

\section{Calculations used to obtain the results in Figures 2 and 3 of the text.}

Eqs 2-5 (above) and $k_{22}$ (obs) $\left(450 \pm 160 \mathrm{M}^{-1} \mathrm{~s}^{-1}\right)$ were used to calculate rate constants for the reactions listed in Figures 2 and 3. To evaluate $\Delta$, the published radii $\left(r_{1}\right)$ of the inorganic complexes were used. For $\mathrm{O}_{2}$ and $\mathrm{O}_{2}{ }^{-}, r_{2}$ was initially left undefined. $\lambda_{11 \text { (out) }}$

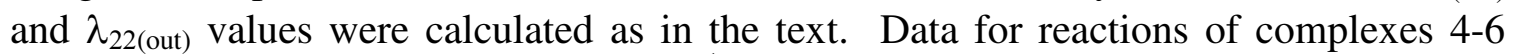
(Figure 2) were taken from the literature ${ }^{1}$ (ionic strength of $175 \mathrm{mM}$ at $298 \mathrm{~K}$ in water, and the hydrodynamic radius, $r_{1}$, of the Keggin anion $\left.=5.6 \mathrm{E}-8 \mathrm{~cm}(5.6 \AA)\right)$. Data for the remaining reactions in Fig. 2 were taken from Bakac and Espenson: Table III, on page 5062 , in ref (2), below. $\mathrm{Ru}(\mathrm{en})_{3}{ }^{2+}$ was noted as an exception in that work, and is not included (or needed) here. 
Calculated values for all 14 reactions were fit to experimental rate constants by minimizing the sum-of-errors squared ( $\log _{10}$ scale), with a single value of $r_{2}$ as the only unknown parameter. The best fit (shown in Figure 2) gave $r_{2}=2.55 \mathrm{E}-8 \mathrm{~cm}(2.55 \AA)$ (this is rounded to 2 significant figures in the text). When used in eqs 3-6, this same value of $r_{2}$ gave the results in Figure 3. No adjustable parameters were included. Published kinetic parameters were from Table II, page 2235 in ref. (3). Data for $\mathrm{Fe}(\mathrm{Cp})_{2}{ }^{+}$were from ref. (2) (Table IV, page 5063).

Constants and conversion factors: Electron charge $(e)=4.8 \mathrm{E}-10$ StatC, viscosity $(\eta)$ of water at $298 \mathrm{~K}=1.33$, dielectric constant of water at $298 \mathrm{~K}=80$, and for work terms, $w_{\text {ii }}, \beta=3.29 \mathrm{E} 7 \mathrm{~cm}^{-1} ; 1 \mathrm{StatC}=1.44 \mathrm{E} 13 \mathrm{kcal} \mathrm{mol}^{-1} \mathrm{erg}^{-1}$ and $1 \mathrm{erg}=(1 \mathrm{StatC})^{2} \mathrm{~cm}^{-1}$.

III. Table S1. Relative Magnitudes of Work Terms, $w_{\mathrm{ij}}$, and $\Delta / 2$ for Reductions of $\mathbf{O}_{2}$. Inspection of the functional dependence of $k_{\text {calc }}$ on $\Delta$ (eqs 5 and 6 in the text) shows why relative size is particularly important in reactions of charged species. The correction, $\Delta$, is linearly combined with the Coulombic work terms, $w_{11}, w_{12}$, and $w_{21}$. Hence, both $W$ (an inverse exponential function of these sums), and $f$ are significantly altered by inclusion of $\Delta$ (Tables $\mathrm{S} 1$ and $\mathrm{S} 2$ ).

Table S1. Relative Magnitudes of Work Terms, $w_{\mathrm{ij}}$, and $\Delta$ for Reductions of $\mathrm{O}_{2}$

\begin{tabular}{ccccccr}
\hline $\begin{array}{c}\text { Electron } \\
\text { donor }^{\mathrm{a}}\end{array}$ & $\begin{array}{c}\text { Effective } \\
\text { radius }^{\mathrm{b}}(\AA)\end{array}$ & $\begin{array}{c}w_{11} \\
\left(\mathrm{kcal} \mathrm{mol}^{-1}\right)\end{array}$ & $\begin{array}{c}w_{21} \\
\left(\mathrm{kcal} \mathrm{mol}^{-1}\right)\end{array}$ & $\begin{array}{c}\Delta / 2 \\
\left(\mathrm{kcal} \mathrm{mol}^{-1}\right)\end{array}$ & $\begin{array}{c}k_{\text {calc }} \\
\left(\mathrm{M}^{-1} \mathrm{~s}^{-1}\right)\end{array}$ & $\begin{array}{c}k_{\text {obs }} \\
\left(\mathrm{M}^{-1} \mathrm{~s}^{-1}\right)\end{array}$ \\
\hline 1 & 4.5 & 1.46 & -1.04 & 2.95 & $5.4 \times 10^{-3}$ & $7.7 \times 10^{-3}$ \\
2 & 4.5 & 1.46 & -1.04 & 2.95 & $5.8 \times 10^{-2}$ & $1.1 \times 10^{-1}$ \\
3 & 4.5 & 1.46 & -1.04 & 2.95 & $1.7 \times 10^{-1}$ & $5.7 \times 10^{-1}$ \\
4 & 5.6 & 1.78 & 0.73 & 3.68 & $9.6 \times 10^{-1}$ & 1.4 \\
5 & 5.6 & 2.97 & 0.98 & 3.68 & 25 & 8.5 \\
6 & 5.6 & 4.46 & 1.22 & 3.68 & $1.4 \times 10^{2}$ & 24 \\
7 & 4.5 & 1.46 & -1.04 & 2.95 & $1.3 \times 10^{2}$ & 43 \\
8 & 3.4 & 2.19 & -1.32 & 2.19 & 59 & 63 \\
9 & 6.8 & 0.77 & -1.15 & 4.43 & $9.7 \times 10^{4}$ & $2.5 \times 10^{5}$ \\
10 & 6.8 & 0.77 & -0.69 & 4.43 & $3.4 \times 10^{5}$ & $6.0 \times 10^{5}$ \\
11 & 6.8 & 0.77 & -0.69 & 4.43 & $4.9 \times 10^{5}$ & $1.5 \times 10^{6}$ \\
12 & 6.8 & 0.77 & -0.69 & 4.43 & $8.3 \times 10^{5}$ & $2.2 \times 10^{6}$ \\
13 & 6.8 & 0.77 & -0.69 & 4.43 & $8.1 \times 10^{6}$ & $1.4 \times 10^{7}$ \\
14 & 6.8 & 0.77 & -0.69 & 4.43 & $8.1 \times 10^{6}$ & $2.5 \times 10^{7}$
\end{tabular}

${ }^{\mathrm{a}}$ Complexes 1-14, as numbered here, are identified in the caption to Figure 2A. ${ }^{\mathrm{b}}$ Except for the Keggin anions (entries 4,5 and $\mathbf{6}$ ), these are averaged radii, equal to $1 / 2\left(d_{1} d_{2} d_{3}\right)^{1 / 3}$, where $d_{1}, d_{2}$ and $d_{3}$ are the diameters of the complexes along the $\mathrm{x}, \mathrm{y}$ and $\mathrm{z}$ axis (method from: Brown, G. M.; Sutin, N. J. Am. Chem. Soc. 1979, 101, 883-892).

IV. Three additional reactions not listed in Figure 3. 
Four of the complexes in Figure 3 are oxidized forms of complexes listed in Figure 2. Given the good fit in Figure 2, it is clear that 1) their published kinetic parameters (selfexchange rate constants and reduction potentials) are accurate, and that the species involved: 2) are not significantly ion paired with electrolyte ions, 3) are stable in both oxidized and reduced forms, and 4) are outer-sphere electron donors. In all, the 6 entries in Figure 3 include reactions of two Fe(III) complexes, three Ru(III) complexes, and one Co(III) complex. These span 8 orders of magnitude in "apparent" $k_{22}$ values, as listed in ref. (3): from $6.9 \times 10^{-5} \mathrm{M}^{-1} \mathrm{~s}^{-1}$ for $\mathrm{FeCp}_{2}{ }^{+}$, to $7.2 \times 10^{3} \mathrm{M}^{-1} \mathrm{~s}^{-1}$ for $\mathrm{Fe}\left(\right.$ edta) $\left(\mathrm{H}_{2} \mathrm{O}\right)^{-}$(' $\mathrm{a}$ ' and ' $\mathbf{b}$ ', respectively, in Figure $2 \mathrm{~B}$ ).

Figure S1 (below) includes all the inorganic complexes listed in Table II, page 2235 of ref. (3). As noted by the authors (3), each of the three problematic cases $\left(\mathrm{Co}(\mathrm{en})_{3}{ }^{3+}\right.$ and $\mathrm{Fe}(\mathrm{CN})_{6}{ }^{3-}$ and $\left.\mathrm{Mo}(\mathrm{CN})_{8}{ }^{3-}\right)$, fail to meet some or all of the above 4 criteria.

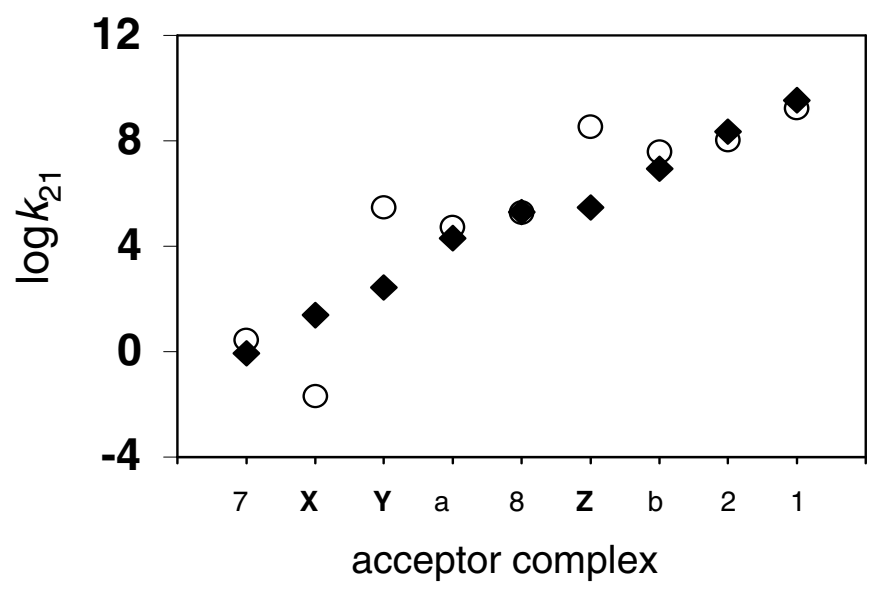

Figure S1. Observed (solid diamonds) and calculated (open circles) rate constants for electron transfer from $\mathrm{O}_{2}^{-}$to 9 inorganic electron acceptors. Complexes 1, 2, 7, 8, a and $\mathbf{b}$ are as in Figure 2B. The others are: $\mathbf{X},\left(\mathrm{Co}(\mathrm{en})_{3}{ }^{3+} ; \mathbf{Y}, \mathrm{Fe}(\mathrm{CN})_{6}{ }^{3-} ; \mathbf{Z}, \mathrm{Mo}(\mathrm{CN})_{8}{ }^{3-}\right.$.

Unlike all other complexes in Figures 2, 3 and S1, Co(en $)_{3}{ }^{2+}(\mathrm{en}=$ ethylenediamine), $\mathbf{X}$, is labile. This adds considerable complexity (and challenge) to determinations of rate constants for self exchange between $\mathrm{Co}(\mathrm{en})_{3}{ }^{3+}$ and $\mathrm{Co}(\mathrm{en})_{3}{ }^{2+}$ (see the original article, ref. (6)), and for the reaction of $\mathrm{Co}(\mathrm{en})_{3}{ }^{3+}$ with $\mathrm{O}_{2}^{-}$(3). In ref. (2), the authors suggest that "the data for Co(en $)_{3}{ }^{3+}$ should probably be excluded". The same, they argue, might be said for $\mathrm{Co}(\mathrm{sep})^{3+}$. However, the sepulchrate complex gives good agreement (the cage complex is non-labile in either $\mathrm{Co}$ (II) and $\mathrm{Co}$ (III) oxidation states), and in hindsight, appears to be better behaved.

The anomalous nature of the cyanide complexes ( $\mathbf{Y}$ and $\mathbf{Z}$ ) was noted Merényi and Lind (7). Calculated values (Figure S1) for these complexes are not meaningful. These 
complexes are subject to extensive ion pairing with electrolyte cations. This affects all kinetic parameters and influences rates of reactions with $\mathrm{O}_{2}$ and $\mathrm{O}_{2}{ }^{-}$. In the original articles in which the self-exchange rate constants are determined ${ }^{4.5}$, a number of assumptions, extrapolations, and electrolyte models are used to estimate rate constants for proposed non-ion-paired (zero-ionic strength) pathways. These are the $k_{11}$ values listed in ref. (3), and used to obtain the results in ref. (3) and here (in Figure S1). The problem with these calculations is that zero-ionic-strength values aren't available for all the other parameters needed in eqs 3-6. On the other hand, actual reactions with $\mathrm{O}_{2}{ }^{-}$are carried out at non-zero ionic strengths, at which (due to cation catalysis or inhibition) there is also no good choice of parameters. Despite all this, the cyanide complexes were included in Figure S1 because colleagues may wish to see the outcome. However, these results are not meaningful because the calculations cannot be done properly with the data currently available.

In summary, good agreement is observed in all cases where the complexes are outersphere reactants whose kinetic parameters are unambiguously established.

\section{Comment on reactions of phenoxyl radicals with $\mathrm{O}_{2}^{-}$}

The reorganization energies in the present work differ from those published by $\mathrm{M}$. Jonsson et. al. (ref. $2 d$ in the text) for reactions between phenoxyl radicals and $\mathrm{O}_{2}^{-}$. The reason for this is explained by Jonsson and co-workers as follows (quoted from ref. $2 d$ ): "The difference between theoretical and best value can be readily explained if the size mismatch between the $\mathrm{O}_{2} / \mathrm{O}_{2}^{-}$and $\mathrm{PhO} \bullet / \mathrm{PhO}^{-}$couples are taken into account." In this context, it should be noted that prior to the work of Jonsson et. al., Meisel (ref. 2c) evaluated reactions between $\mathrm{O}_{2}{ }^{-}$and quinines. Excellent fits were seen in plots of $\log k$ vs. $\log K$. (In fact, the scatter in that data is much less than that reported by Jonsson in ref. 2d.) However, the $k_{22}$ value for self exchange between $\mathrm{O}_{2}$ and $\mathrm{O}_{2}^{-}$suggested by Meisel's data was ca. $10^{8} \mathrm{M}^{-1} \mathrm{~s}^{-1}, 6$ orders of magnitude too large. Another pertinent issue is that reactions of phenoxyl radicals or quinones are likely subject to "orientational restrictions" that fail to comply with the assumptions of the Marcus model, which for homogeneous reactions describes electron-transfer between spherical molecules. This may be true as well for reactions of $\mathrm{O}_{2}$ and $\mathrm{O}_{2}^{-}$, but is less of an issue for the more approximately spherical coordination complexes.

\section{References}

1. Geletii, Y. V., Hill, C. L., Atalla, R. H. \& Weinstock, I. A. Reduction of $\mathrm{O}_{2}$ to superoxide anion $\left(\mathrm{O}_{2}{ }^{--}\right)$in water by heteropolytungstate cluster-anions. J. Am. Chem. Soc. 128, 17033 - 17042 (2006).

2. Zahir, K., Espenson, J. H. \& Bakac, A. Reactions of polypyridylchromium(II) ions with oxygen: Determination of the self-exchange rate constant of $\mathrm{O}_{2} / \mathrm{O}_{2}{ }^{-}$. J. Am. Chem. Soc. 110, 5059-5063 (1988). 
3. McDowell, M. S., Espenson, J. H. \& Bakac, A. Kinetics of Aqueous Outer-Sphere electron-transfer reactions of superoxide Ion. Implications concerning the $\mathrm{O}_{2} / \mathrm{O}_{2}{ }^{-}$selfexchange rate constant. Inorg. Chem. 23, 2232-2236 (1984).

4. Zehavi, D. \& Rabani, J. Pulse radiolysis of the aqueous ferro-ferricyanide system. I. The reactions of $\mathrm{OH}, \mathrm{HO}_{2}$, and $\mathrm{O}_{2}^{-}$radicals. J. Phys. Chem. 76, 3073-3709 (1972).

5. Faraggi, M. Steady state and pulse radiolysis studies of molybdenum octacyanate in aqueous solutions. J. Phys. Chem. 80, 2316-2320 (1976).

6. Dwyer, F. P. \& Sargeson, A. M. The rate of electron transfer between the tris(ethylenediamine)-cobalt(II) and cobalt(III) ions. J. Phys. Chem., 65, 1892-1894 (1961).

7. Merényi, G.; Lind, J.; Jonsson, M. J. Am. Chem. Soc. 1993, 115, 4945-4946. 